\title{
Características produtivas do tomateiro submetido a diferentes níveis de sais, na água de irrigação ${ }^{1}$
}

\author{
Bernardete C. Oliveira ${ }^{2}$, Maria A. A. Cardoso ${ }^{3}$, Juliana C. de Oliveira ${ }^{4}$, Francisco A. de Oliveira ${ }^{5}$ \& Lourival F. Cavalcante $^{5}$
}

\section{RESUMO}

No período de junho a novembro de 1999, conduziu-se este trabalho em casa-de-vegetação do DSER/CCA/UFPB, no município de Areia, PB, com o objetivo de se avaliar os efeitos de sais na água de irrigação em relação a algumas características do desenvolvimento da cultura do tomateiro (Lycopersicum esculentum sp), cultivar Santa Rosa. Utilizou-se água proveniente do açude de Jacaré, no município de Remígio, PB, com condutividade elétrica de $24,5 \mathrm{dS} \mathrm{m}^{-1}$. Os tratamentos se constituíram de: água de chuva $\left(\mathrm{T}_{1}-0,01 \mathrm{dS} \mathrm{m}^{-1}\right)$ e diluições da água do açude com água de chuva, nas proporções de 1:4 $\left(T_{2}-5,7 d S m^{-1}\right), 1: 3\left(T_{3}-6,8 d S m^{-1}\right), 1: 2\left(T_{4}-8,3 d S m^{-1}\right), 1: 1\left(T_{5}-12,7 d S m^{-1}\right)$ e 1:0 $\left(T_{6}-24,5 d S m^{-1}\right)$. Adotou-se o delineamento experimental em blocos ao acaso, com três repetições, sendo a unidade experimental com capacidade para $20 \mathrm{~L}$, contendo $15 \mathrm{~kg}$ de solo secado ao ar. Os eventos de irrigação variaram de um a dois dias. Foram avaliadas: altura de plantas (AP), área foliar (AF), produção de biomassa seca (BS), produção de frutos (PF) e evapotranspiração da cultura (ETc). Os níveis de sais na água de irrigação reduziram significativamente $(p \leq 0,01)$ os valores das variáveis analisadas, com efeito linear sobre a AP e BS, e quadrático para AF, PF e ETc. A ETc se correlacionou positivamente com a AF.

Palavras-chave: Lycopersicum esculentum sp., salinidade, tolerância, desenvolvimento, evapotranspiração

\section{Productive characteristics of tomato crop submitted to different levels of salts in the irrigation water}

\begin{abstract}
During the period of June to November of 1999, the study was carried out in a greenhouse of the DSER/CCA/UFPB, in the municipality of Areia in the State of Paraiba, Brazil, with the objective of verifying the effects of salts in the irrigation water on some development characteristics of tomato crop (Lycopersicum esculentum sp), cultivar Santa Rosa. The water used was from Jacaré reservoir located in the Remígio city, with electrical conductivity of $24.5 \mathrm{dS} \mathrm{m}^{-1}$. The treatments consisted of: rainfall water $\left(\mathrm{T}_{1}-0.01 \mathrm{dS} \mathrm{m}^{-1}\right)$ and dilutions of the reservoir water with rainfall water, in the proportions of 1:4 $\left(\mathrm{T}_{2}-5.7 \mathrm{dS} \mathrm{m}^{-1}\right), 1: 3\left(\mathrm{~T}_{3}-6.8 \mathrm{dS} \mathrm{m}^{-1}\right), 1: 2\left(\mathrm{~T}_{4}-8.3 \mathrm{dS} \mathrm{m}^{-1}\right), 1: 1\left(\mathrm{~T}_{5}-12.7 \mathrm{dS} \mathrm{m}^{-1}\right)$ and 1:0 $\left(\mathrm{T}_{6}-24.5 \mathrm{dS} \mathrm{m}^{-1}\right)$. The experimental design consisted of randomized blocks with 3 repetitions, the experimental unit being recipient with capacity for $20 \mathrm{~L}$, containing $15 \mathrm{~kg}$ of air dried soil. The irrigation events varied from one to two days. The height of plants, leaf area, production of the dry matter, production of fruits and evapotranspiration of the crop were evaluated. The levels of salts in the irrigation water reduced significantly $(p \leq 0.01)$ the values of the variables analyzed, with a linear effect on height and dry matter production and quadratic effect on leaf area, production of fruits and evapotranspiration. The latter was correlated positively to leaf area.
\end{abstract}

key words: Lycopersicum esculentum sp., salinity, tolerance, development, evapotranspiration

1 Extraído da Dissertação de Mestrado do primeiro autor, apresentada ao Curso de Pós-Graduação em Mestrado Interdisciplinar em Saúde Coletiva da Universidade Estadual da Paraíba, Campina Grande, PB

2 Depto de Ciências Biológicas/UEPB, Campina Grande, PB. Fone: (83) 3341-3300. E-mail: julierafa@uol.com.br

${ }^{3}$ Farmacêutica, UEPB. E-mail: mcadoso@opeline.com.br

${ }^{4}$ Discente do Curso de Direito da UEPB. Fone (83) 3321-1540. E-mail: julierafa@uol.com.br

${ }_{5}^{5}$ Depto de Solos e Eng. Rural, CCA/UFPB, CEP 58397-000, Areia, PB. Fone: (83) 3362-2300 ramal 257, Bolsistas do CNPq, E-mail: oliveira.@cca.ufpb.br; lofeca@cca.ufpb.br 


\section{INTRODUÇÃO}

Dentre as hortaliças cultivadas no Brasil, o tomate (Lycopersicum esculentum sp) é a mais importante, considerando-se os aspectos socioeconômicos (Martins, 1991). É cultivada em todos os estados da Federação com produção de 2,5 milhões de toneladas, das quais cerca de $20 \%$ são provenientes do estado de São Paulo, 18\% do Nordeste e 1,8\% da Paraíba (IBGE, 1999). A produção paraibana é insuficiente para atender a demanda de sua população, o que suscita esforços no sentido de se incrementar as produções locais, explorando principalmente as áreas semi-áridas da região, através do uso da irrigação.

A socioeconomia da população rural brasileira, em especial do semi-árido paraibano depende, em geral, das condições edafoclimáticas da região e do uso dos recursos naturais de solo-água-planta disponíveis. Estudos do World Bank/ UNDP (1990) prevêem que no ano 2050 a população mundial deverá ultrapassar os 10 bilhões de habitantes; portanto, em termos atuais, um aumento de cerca de $63 \%$ o que se constituirá em correspondente aumento na demanda por alimentos. Segundo as previsões, grande parte desse aumento demográfico deverá concentrar-se nos países em desenvolvimento nos quais se localiza a maior parte dos solos afetados por sais, sobretudo nas regiões áridas e semi-áridas. A demanda de alimentos para atender significativa parcela da população mundial, só tem sido possível através da prática da irrigação. Atualmente, $40 \%$ do total das colheitas agrícolas a nível mundial e 35\% a nível nacional, são provenientes da prática de irrigação (Christofidis, 2001). Neste contexto, a incorporação das áreas afetadas por sais ou em estágios de salinidade/sodicidade ao processo produtivo de alimentos, constitui-se de fundamental importância do ponto de vista socioeconômico (Fageria \& Gheyi, 1997).

O acúmulo de sais no solo poderá ser de origem primária (intemperismo químico da rocha básica), ou secundária, causado pelos sais contidos na água de irrigação (Richards, 1974). Sob as condições climáticas presentes no semi-árido, o aumento do teor de sais solúveis no solo é um processo natural, pois o déficit de precipitação em relação à evapotranspiração aumenta a concentração de sais nas camadas superficiais do solo; neste processo, o uso da irrigação implica necessariamente na incorporação gradativa de sais no solo, sobretudo nas camadas de atividade radicular, com reflexos depressivos sobre o crescimento e desenvolvimento das culturas (Richards, 1974; Yeo, 1999). Estudos confirmam que a água de irrigação é o maior veículo causador de problemas relacionados à salinidade e/ou sodicidade dos solos, aliada ao manejo inadequado das áreas irrigadas pode acelerar o processo, notadamente em condições de drenagem deficiente (Richards, 1974; Audry \& Suassuna, 1990; Oliveira, 1997), e incorporar ao solo várias toneladas de sais ha-1 ano-1 (Macêdo, 1988). Estudos têm comprovado, em especial para o semi-árido do Nordeste brasileiro, que as águas normalmente utilizadas na irrigação se apresentam, na maioria das vezes, com concentrações de sais que têm concorrido para acelerar os problemas relacionados à salinidade e/ou à sodicidade dos solos, reduzindo sobremaneira a produção agrí- cola nas áreas irrigadas (Leprun, 1983; Costa et al., 1982; Laraque, 1989; Audry \& Suassuna, 1990; Medeiros, 1992).

As conseqüências da salinidade/sodicidade do meio inibindo as características de crescimento e desenvolvimento das plantas, são constatadas de três maneiras: por estresse salino, devido ao efeito osmótico, restringindo a disponibilidade de água (estresse hídrico) e absorção de nutrientes; por toxicidade, através do acúmulo de íons específicos e por desordem nutricional, com reflexos morfológicos, estruturais e metabólicos (Ayers \& Westcot, 1991; Shannon, 1997; Chusman, 2001). O grau em que cada componente do estresse salino influencia o crescimento das plantas, é dependente de muitos fatores destacando-se, entre eles, espécie vegetal, cultivar, estádio fenológico, composição salina do meio e condições edafoclimáticas (Shannon, 1997, Alian et al., 2000). Para Lima et al. (1997) as plantas tolerantes à salinidade, designadas halófitas, podem tolerar até $15 \mathrm{~g} \mathrm{~L}^{-1}$ de cloreto de sódio, equivalente à metade da concentração da água do mar. Enquanto as plantas tolerantes absorvem os sais e os acumulam em suas folhas, para estabelecer um equilíbrio osmótico com o baixo potencial da água presente no solo, as sensíveis não são capazes de realizar o ajuste osmótico e sofrem com o decréscimo de turgor, levando-as ao estresse hídrico, por osmose.

Rush \& Epstein (1976) irrigando duas espécies de tomateiro com água do mar em diferentes diluições, verificaram que as plantas de Lycopersicum cheesmanii sobreviveram, mesmo quando cultivadas em solução com $70 \%$ da água do mar, enquanto as Lycopersicum esculentum não sobreviveram quando a concentração superou a 50\%. Pequenas modificações genéticas poderiam conferir maior tolerância a salinidade para as plantas sensíveis, o que permitiria que águas de qualidade marginal, ou mesmo a água do mar, pudessem ser utilizadas na irrigação, reduzindo a necessidade de desmatamento para incorporar terras produtivas ao sistema agrícola. Trabalhos nos quais genes de outras espécies de plantas são adicionados ao código genético do tomateiro, visando aumento da tolerância à salinidade, têm sido desenvolvidos, resultando em plantas que chegam a tolerar salinidade 50 vezes maior que plantas não-transgênicas (Travis, 2001)

Segundo Doorenbos \& Kassam (1994) o tomateiro é considerado uma cultura moderadamente sensível à salinidade do solo, particularmente na fase do desenvolvimento inicial, cuja característica é atribuída ao grupo de culturas que apresentam 100\% do rendimento potencial, em condições de salinidade do extrato de saturação do solo entre 1,3 e 3,0 dS m ${ }^{-1}$ (Ayers \& Westcot, 1991). Para os autores, águas com condutividade elétrica superiores a 3,0 dS m-1 sofrem severas restrições para uso em irrigação. Shalhevet \& Yaron (1973) verificaram redução significativa na produção do tomateiro e diminuição no tamanho do fruto em solos com condutividade elétrica do extrato de saturação superior a 3,5 dS m². Por outro lado, Blanco (2004) não observou efeito significativo dos tratamentos de nitrogênio e potássio em ambiente com água de irrigação com condutividade elétrica de $9,5 \mathrm{dS} \mathrm{m} \mathrm{m}^{-1}$. Objetivou-se, neste trabalho, avaliar algumas características do crescimento e desenvolvimento do tomateiro submetida a diferentes níveis de sais na água de irrigação. 


\section{MATERIAL E MÉTODOS}

O estudo foi conduzido no período de junho a novembro de 1999, em galpão telado coberto com telhas de fibra de vidro transparente, pertencente ao Centro de Ciências Agrárias da Universidade Federal da Paraíba (CCA/UFPB), localizado no município de Areia, PB.

Como substrato utilizou-se material do horizonte Ap, coletado nos $20 \mathrm{~cm}$ superficiais do perfil de um Latossolo Vermelho Amarelo (EMBRAPA, 1999), da fazenda experimental Chã do Jardim, pertencente ao CCA/UFPB, situada na microrregião do Brejo Paraibano, no município de Areia, PB. $\mathrm{O}$ material do solo apresentou textura franco-argilo-arenosa, com frações granulométricas: $542 \mathrm{~g} \mathrm{~kg}^{-1}$ de areia total, $92 \mathrm{~g} \mathrm{~kg}^{-1}$ de silte e $366 \mathrm{~g} \mathrm{~kg}^{-1}$ de argila a análise química revelou: reação do solo em água ( $\mathrm{pH}=4,70), 2,60 \mathrm{cmol}_{\mathrm{c}} \mathrm{dm}^{-3}$ de Ca,. 1,90 $\mathrm{cmol}_{\mathrm{C}} \mathrm{dm}^{-3}$ de $\mathrm{Mg}, 0,65 \mathrm{cmol}_{\mathrm{C}} \mathrm{dm}^{-3}$ de Al trocável, 3,60 $\mathrm{mg} \mathrm{dm}^{-3}$ de fósforo disponível (Mehlich 1), $85,8 \mathrm{mg} \mathrm{dm}^{-3}$ de potássio, $31,30 \mathrm{~g} \mathrm{~kg}^{-1}$ de matéria orgânica e $0,47 \mathrm{dS} \mathrm{m}^{-1}$ de condutividade elétrica (EMBRAPA, 1997).

Procedeu-se à correção do solo através da calagem com calcário dolomítico cuja quantidade foi estimada com base no alumínio trocável no solo e no poder relativo de neutralização total (PRNT) do calcário. Após a aplicação do corretivo, antes do plantio, o solo permaneceu incubado durante 50 dias, com revolvimento do material do solo e irrigação semanal. Segundo os resultados da análise de fertilidade e da exigência da cultura, o solo recebeu uma adubação corretiva e de manutenção, constituída por $200 \mathrm{~kg} \mathrm{ha}^{-1}$ de $\mathrm{N}$, $300 \mathrm{~kg} \mathrm{ha}^{-1}$ de $\mathrm{P}_{2} \mathrm{O}_{5}$ e $100 \mathrm{~kg} \mathrm{ha}^{-1}$ de $\mathrm{K}_{2} \mathrm{O}$ usando-se, como fontes dos insumos, o sulfato de amônio, superfosfato simples e cloreto de potássio, respectivamente.

Para avaliar algumas características do desenvolvimento da cultura do tomateiro, cultivar Santa Rosa, utilizou-se água proveniente do açude de Jacaré, no município de Remígio, PB, que, após a análise, apresentou: $\mathrm{pH}=7,9$; condutividade elétrica $24,5 \mathrm{dS} \mathrm{m}{ }^{-1}$; cátions em $\mathrm{mmol}_{\mathrm{C}} \mathrm{L}^{-1}\left(\mathrm{Ca}^{2+}, \mathrm{Mg}^{2+}, \mathrm{K}^{+}, \mathrm{Na}^{+}\right.$, respectivamente, 16,30, 95,20, 2,15 e 94,00) e de ânions em $\mathrm{mmol}_{\mathrm{C}} \mathrm{L}^{-1}\left(\mathrm{HCO}_{3}{ }^{-}, \mathrm{SO}_{4}{ }^{2-}, \mathrm{Cl}^{-}\right.$, respectivamente, 4,20, 1,25 e 257,00 ,) e relação de adsorção de sódio $12,50\left(\mathrm{mmol}_{\mathrm{C}} \mathrm{L}^{-1}\right)^{1 / 2}$. Os tratamentos se compuseram de seis níveis de sais na água de irrigação: água de chuva $\left(T_{1}-0,01 \mathrm{dS} \mathrm{m}^{-1}\right)$ e diluições da água do açude, com água de chuva, nas proporções de 1:4 $\left(\mathrm{T}_{2}-5,7 \mathrm{dS} \mathrm{m}^{-1}\right), 1: 3\left(\mathrm{~T}_{3}-6,8 \mathrm{dS} \mathrm{m}^{-1}\right), 1: 2\left(\mathrm{~T}_{4}-8,3 \mathrm{dS} \mathrm{m}^{-1}\right)$, 1:1 $\left(\mathrm{T}_{5}-12,7 \mathrm{dS} \mathrm{m}^{-1}\right)$ e 1:0 $\left(\mathrm{T}_{6}-24,5 \mathrm{dS} \mathrm{m}^{-1}\right)$. Na época da co- leta da água do açude o reservatório se encontrava com cerca de $20 \%$ de sua capacidade.

Adotou-se o delineamento experimental em blocos ao acaso completos, com seis tratamentos e três repetições. A unidade experimental foi representada por um balde plástico, com capacidade para $20 \mathrm{~L}$, contendo $15 \mathrm{~kg}$ de solo secado ao ar e passado em peneira de $6 \mathrm{~mm}$. Na base de cada vaso foi colocado um dispositivo de drenagem para eliminar o excesso de água da irrigação e deixar o solo com umidade em capacidade de campo. As irrigações foram processadas em intervalo de rega de um a dois dias, procurando-se manter, sempre, o solo próximo da capacidade máxima de retenção de umidade ou capacidade de campo.

Procedeu-se ao semeio em 18/06/1999 e à colheita, em 26/ 09/1999. Como características da cultura, foram avaliados: altura de plantas, área foliar, produção da biomassa seca da parte aérea, rendimento de frutos e evapotranspiração, sendo esta estimada semanalmente pela diferença entre a água aplicada na irrigação e o excesso drenado. Os resultados foram submetidos a análise de variância (teste F) e de regressão polinomial, em que a escolha do modelo recaiu para o maior grau significativo (Gomes, 1990).

\section{RESULTADOS E DISCUSSÃO}

Segundo a análise de variância, as concentrações de sais na água de irrigação influenciaram significativamente $(\mathrm{p} \leq 0,01)$ os resultados das varáveis analisadas; ressalta-se que o desdobramento dos efeitos dos tratamentos, através da análise de regressão, revelou efeito linear sobre a altura de plantas e a produção de matéria seca e quadrática para área foliar, rendimento de frutos e evapotranspiração da cultura (Tabela 1).

A Figura 1A apresenta os resultados da altura de plantas, concluindo-se que através da regressão polinomial é possível constatar efeito linear $(\mathrm{p} \leq 0,01)$ decrescente, cujo modelo estimado permite afirmar-se, teoricamente, que o decréscimo na altura de plantas foi da ordem de $4,76 \mathrm{~cm}$ por aumento unitário na condutividade elétrica da água de irrigação; portanto, a redução na altura das plantas, causada pelos tratamentos, seria de $18,22,26,40$ e $78 \%$ para os níveis de salinidade $\left(5,7,6,8,8,3,12,7\right.$ e $\left.24,5 \mathrm{dS} \mathrm{m}^{-1}\right)$, respectivamente, em relação ao tratamento com água de chuva $\left(\mathrm{T}_{1}-0,01 \mathrm{dS} \mathrm{m}^{-1}\right)$. Esta redução na altura das plantas

Tabela 1. Resultados da análise de variância (quadrados médios) referentes à altura de plantas (AP), área foliar (AF), matéria seca (MS) da parte aérea, produção de frutos (PF) e evapotranspiração da cultura (ETc) do tomate submetido a diferentes níveis de sais na água de irrigação

\begin{tabular}{|c|c|c|c|c|c|c|}
\hline \multirow{2}{*}{ Causa da Variação } & \multirow{2}{*}{ GL } & \multicolumn{5}{|c|}{ Quadrado Médio } \\
\hline & & AP & $\mathrm{AF}$ & MS & PF & ETc \\
\hline Bloco & 2 & $92,2^{\mathrm{ns}}$ & $25.645,2^{\text {ns }}$ & $4,4^{\mathrm{ns}}$ & $830,0^{\text {ns }}$ & $5,4^{\mathrm{ns}}$ \\
\hline Tratamento & 5 & $5.200,1^{* *}$ & $4.826 .280,4^{* *}$ & $1.766,3^{\star *}$ & $101.910,7^{\star *}$ & $240,3^{\star \star}$ \\
\hline Regressão linear & 1 & $24.928,3$ ** & $22.178 .650,1^{* *}$ & 144,0 ** & $297.923,6^{* *}$ & $916,3^{* *}$ \\
\hline Regressão quadrática & 1 & $128,3^{\text {ns }}$ & $1.014 .603,6^{\star *}$ & $0,1^{\text {ns }}$ & $63.663,7^{\star * *}$ & $108,8^{* *}$ \\
\hline Resíduo & 10 & 96,3 & $57.337,2$ & 9,9 & $1.069,7$ & 1,9 \\
\hline Coef. de variação - \% & & 9,4 & 11,7 & 7,6 & 5,3 & 8,2 \\
\hline
\end{tabular}

${ }^{\text {ns }} \mathrm{e}^{* *}$ : não significativo e significativo a $1 \%$ de probabilidade, pelo teste "F" 

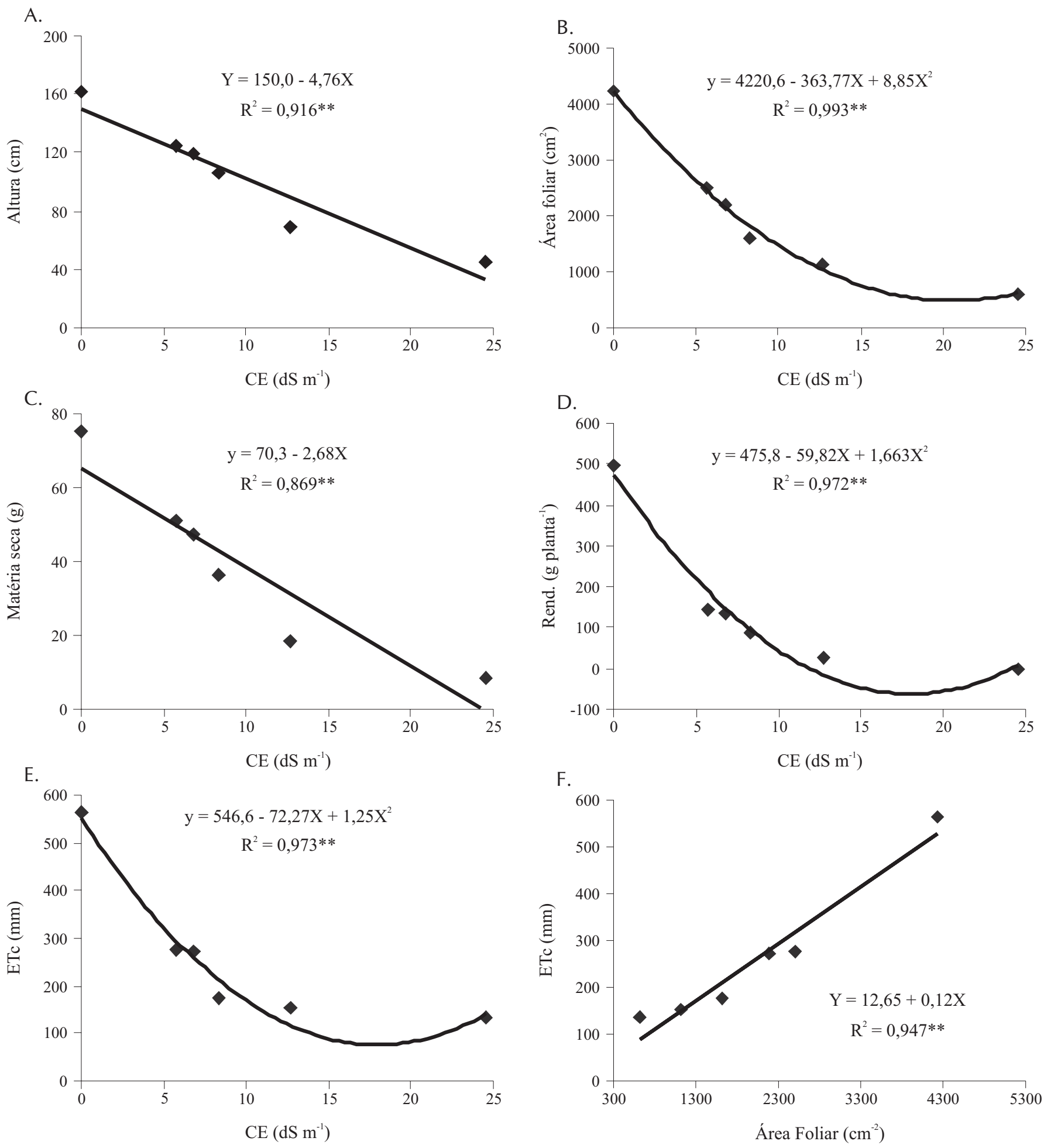

Figura 1. Altura de planta (A), área foliar (B), matéria seca (C), rendimento de frutos(D), Evapotranspiração de cultura (E), em função dos níveis de sais na água de irrigação e evapotranspiração da cultura (ETc) em função da área foliar (F)

registra o comportamento da sensibilidade do tomateiro aos níveis de salinidade contidos na água de irrigação confirmando, desta forma, o comportamento da cultura frente ao ambiente salino apresentado por Doorenbos \& Kassam (1994) e Ayers \& Westcot (1991). Egídio Neto (2004) também constatou que concentração elevada de $\mathrm{NaCl}$ na solução nutritiva provoca redução no crescimento da cultura.

De acordo com a análise de regressão, a área foliar (AF) também decresceu com o aumento dos sais na água de irrigação, cujos resultados se ajustaram satisfatoriamente a uma equação do $2^{\circ}$ grau (Figura $1 \mathrm{~B}$ ), e o modelo obtido permite afirmar-se que o menor resultado da $\operatorname{AF}\left(482,5 \mathrm{~cm}^{2}\right)$ seria atingido, teoricamente, com $20,5 \mathrm{dS} \mathrm{m}^{-1}$ de sais na água de irrigação mas, com base nos tratamentos utilizados a redução na AF foi da ordem de 42,3, 51,1, 57,1, 75,6 e 85,3\% para os níveis de sais 5,7, 6,8, 8,3, 12,7 e 24,5 dS m-1, 
respectivamente, em relação ao tratamento $\left(\mathrm{T}_{1}-0,01 \mathrm{dS} \mathrm{m}^{-1}\right)$. De acordo com o coeficiente de determinação, os resultados obtidos são explicados em 99\%, pela presença dos tratamentos. O efeito osmótico restringe a disponibilidade de água no solo para a cultura e concorre para a adaptação das plantas ao estresse hídrico (Richards, 1974), com redução progressiva da superfície transpiratória, fotossinteticamente ativa, segundo os níveis de sais usados nos tratamentos.

Os resultados da biomassa seca (BS) e da produção de frutos (PF) da cultura do tomateiro, decresceram de forma significativa ( $\mathrm{p} \leq 0,01)$ com os níveis de sais na água de irrigação constatando-se, de acordo com os modelos obtidos, a ocorrência de efeito linear para BS (Figura 1C) e quadrático para PF (Figura 1D). Segundo as equações estimadas, é possível se afirmar que, teoricamente, o decréscimo na BS foi da ordem de 2,68 g planta ${ }^{-1}$ e, para a PF, a redução foi quadrática. De acordo com os tratamentos e o modelo obtido, a BS cresceu em 21,7, 25,9, 31,6, 48,4 e 93,4\%, respectivamente, para os níveis de sais 5,7, 6,8, 8,3, 12,7 e $24,5 \mathrm{dS} \mathrm{m}^{-1}$ na água de irrigação em relação ao tratamento $\left(\mathrm{T}_{1}-0,01 \mathrm{dS} \mathrm{m}^{-1}\right)$. Os resultados obtidos estão compatíveis com Ayers \& Westcot (1991) quando atribuem rendimento potencial zero do tomateiro em manejo da irrigação com $8,4 \mathrm{dS} \mathrm{m}^{-1}$ de sais na água de irrigação e $13,0 \mathrm{dS} \mathrm{m}^{-1}$ no extrato de saturação do solo. Egídio Neto (2004) constatou que a elevada concentração de $\mathrm{NaCl}$ na solução nutritiva promoveu redução significativa na produção da matéria seca e no rendimento de frutos da cultura.

A Figura 1E apresenta os resultados da evapotranspiração da cultura, ETc, em que, de acordo com a análise de regressão polinomial, a ETc decresceu $(\mathrm{p} \leq 0,01)$ segundo o modelo quadrático com os níveis de sais na água de irrigação. Segundo a equação estimada, o consumo de água pelas plantas atingiu um mínimo teórico de aproximadamente $100 \mathrm{~mm}$ para uma CE de $19 \mathrm{dS} \mathrm{m}^{-1}$, mas, segundo os tratamentos utilizados, a ETc decresceu de 41,8, 48,2, 56,0, 72,9 e 74,6\%, respectivamente, para os níveis de sais 5,7, 6,8, 8,3, 12,7 e $24,5 \mathrm{dS} \mathrm{m}^{-1}$ na água de irrigação em relação ao tratamento $\left(\mathrm{T}_{1}-0,01 \mathrm{dS} \mathrm{m}^{-1}\right)$. De acordo com o coeficiente de determinação, os resultados obtidos foram explicados em 99\% pela presença dos tratamentos. A redução no consumo de água pela cultura com o aumento da salinidade na água de irrigação é interpretada como uma adaptação das plantas ao estresse salino, reduzindo a área foliar (Figura 1B) fotossinteticamente ativa diminuindo, por conseguinte, o consumo de água pelas plantas, visto que a pressão osmótica do meio aumenta a dificuldade da cultura em absorver água (Richards, 1974); por outro lado, a água de chuva $\left(\mathrm{T}_{1}-0,01 \mathrm{dS} \mathrm{m}^{-1}\right)$ proporcionou a máxima ETc, $547 \mathrm{~mm}$, cujo valor concorda com os dados obtidos por Lima et al. (1994), 479 mm, para o tomate na região de Teresina, PI, e com Doorenbos \& Kassam (1994) que atribuem consumo de água pelo tomate na faixa de 400 a $600 \mathrm{~mm}$, em condições de campo e ciclo da cultura, entre 90 a 120 dias.

$\mathrm{O}$ tratamento $\mathrm{T}_{2}\left(5,7 \mathrm{dS} \mathrm{m}^{-1}\right)$ representaria uma simulação das condições de salinidade da água do açude Jacaré, quando estivesse cheio pelas águas de chuva; mesmo assim, causaria redução em 12, 18, 21, 42 e 42\%, respectivamente, nas varáveis PF, BS, AP, AF e ETc.

A Figura 1F apresenta os resultados da evapotranspiração da cultura (ETc) em função da área foliar (AF) das plantas. Observa-se estreita correlação entre a ETc e a AF evidenciando que um aumento na cobertura do solo com área foliar fotossinteticamente ativa deverá promover, em condições similares de umidade e temperatura, uma ETc evidentemente maior. O modelo que melhor se ajustou aos dados da ETc contra a AF, resultou em uma equação linear positiva, sinalizando para uma associação direta da superfície transpirante da cultura com sua demanda hídrica, ensejando que se afirme, ainda de acordo com o modelo obtido, que para cada acréscimo de $100 \mathrm{~cm}^{2}$ na área foliar da cultura o consumo de água pelas plantas aumentaria em $12 \mathrm{~mm}$.

\section{CONCLUSÕES}

1. Os níveis de sais na água de irrigação reduziram, de forma significativa, a altura de plantas, área foliar, produção da biomassa seca da parte aérea, produção de frutos e a evapotranspiração da cultura do tomate.

2. Os efeitos para altura de plantas e biomassa seca, foram de natureza linear e quadrática para área foliar, produção de frutos e evapotranspiração da cultura.

3. As variáveis que menos toleraram o ambiente salino foram, em ordem decrescente, biomassa seca > área foliar > altura de plantas > evapotranspiração > produção de frutos.

\section{LITERATURA CITADA}

Alian, A.; Altman, A.; Heuer, B. Genotypic diference in salinity and water stress tolerance of fresh tomato cultivars. Palnt Science. Columbus, v.152, n.1, p.59-65. 2000.

Audry, P.; Suassuna, J. A qualidade da água na irrigação do trópico semi-árido. Um estudo de caso. In: Seminário Franco Brasileiro de Pesquisa em Irrigação, 1990, Recife. Anais... Recife: SUDENE, 1990. p.147-153.

Ayers, R. S.; Westcot, D. A. A qualidade da água na agricultura, 1991. 218p. (Estudos FAO: Irrigação e Drenagem, 29 Revisado)

Blanco, F. F. Tolerância do tomateiro a salinidade sob fertirrigação e calibração de medidores de íons específicos para determinação de nutrientes na solução e na planta. Piracicaba: ESALQ, 2004. 134p. Tese Doutorado

Christofidis, D. Prática de irrigação no mundo. Item: Brasília, ABID, n.49, p.8-13. 2001.

Chusman, J. C. Osmoregulation in plants: implications for agriculture. American Zoologist, New York, v.41, n.4, p.758769, 2001.

Costa, R. G.; Carvallo, H.; Gheyi, H. R. Qualidade da água de irrigação da microrregião homogênea de Catolé do Rocha, PB. Revista Brasileira da Ciência do Solo, Campinas, v.6, n.3, p.242-244, 1982.

Doorenbos, J.; Kassam, A. H. Efeito da água no rendimento das culturas. Campina Grande: UFPB, 1994. 306p. il. Estudos da FAO: Irrigação e Drenagem, 33 
Egídio Neto, B. Efeito da salinidade sobre quatro cultivares de tomateiro. 1985. Recife: Universidade Federal Rural de Pernambuco. Dissertação Mestrado <http:www.ufrpe.br/química/ medidio.htm>. 20 Nov. 2004.

EMBRAPA - Empresa Brasileira de Pesquisa Agropecuária. Centro Nacional de Pesquisa de Solos. Manual de nétodos de análise de solo 2. ed. Rio de Janeiro: Embrapa - CNPS, 1997, 212p. Documento 1.

EMBRAPA - Empresa Brasileira de Pesquisa Agropecuária. Centro Nacional de Pesquisa de Solos (Rio de Janeiro). Sistema brasileiro de classificação de solos. Brasília: EMBRAPA. 1999, 412p.

Fageria, N. K.; Gheyi, H. R. Melhoramento genético de plantas e seleção de cultivares. In: Gheny, H. R.; Queiroz, J. E.; Medeiros, J. F. de. (ed.) Manejo e controle da salinidade na agrigultura irrigada. Campina Grande: UFPB-SBEA, 1997, p.363-383.

Gomes, F. P. Curso de estatística experimental. Piracicaba: Nobel, 1990. 468p

IBGE - Instituto Brasileiro de Geografia e Estatística. Levantamento sistemático da produção agrícola. Rio de Janeiro, v.12, n.4, p.1-73, 1999.

Laraque, A. Estudo e previsão da qualidade química da água dos açudes do Nordeste. Recife: SUDENE, 1989. 97p. Série Hidrológica, 26.

Leprun, J. C. Primeira avaliação das águas superficiais do Nordeste. In: Relatório Final do Convênio Manejo e Conservação do Solo do Nordeste Brasileiro. Recife: SUDENE - DRN, 1983. p.91-141. Convênio SUDENE/ORSTOM.

Lima, L. A. Efeitos de sais no solo e na planta. In: Gheyi, H. R.; Queiroz, J. E.; Medeiros, J. F. de. (ed.) Manejo e controle da salinidade na agricultura irrigada. Campina Grande: UFPB, 1997, p.113-136.
Lima, M. G.; Leal, F. R.; Setúbal, J. W. Evapotranspiração máxima e coeficiente de cultura para o tomateiro em Teresina, PI. Revista Brasileira de Agrometeorologia. Santa Maria, v.2, p.29-32. 1994.

Macêdo, L. de S. Salinidade em áreas irrigadas. João Pessoa: EMEPA. 1988, 11p. Comunicado Técnico, 38

Martins, G. Produção de tomate em ambiente protegido. In: Encontro Nacional de Produção e Abastecimento de Tomate, 2., Jaboticabal, 1991. Anais.., Jaboticabal: FUNEP, 1991. p.219-230.

Medeiros, J. F. A qualidade da água de irrigação e evolução de salinidade nas propriedades assistidas pelo "GAT" nos Estados do RN, PB e CE. Campina Grande: Universidade Federal da Paraíba. 1992. 173p. Dissertação Mestrado

Oliveira, M. Gênese, classificação e extensão de solos afetados por sais. In: Gheyi, H.R.; Queiroz, J. E.; Medeiros, J. F. de (ed.) Manejo e controle da salinidade na agricultura irrigada. Campina Grande: SBEA/UFPB, p.1-35, 1997.

Richards, L. A. Diagnostico y rehabilitacion de suelos salinos y sodicos. DAEUA. Mexico. Editorial Limusa, 1974, 172p.

Rush, D. W.; Epstein, E. Genotypic responses to salinity: differences between salt-sensitive and salt- tolerant genotipres of the tomato. Plant Physiology. Minneapolis v.57, n.2, p.162- 166. 1976.

Shalhevet, J.; Yaron, B. Effect of soil and water salinity on tomato growth. Plant and Soil The Hague, v. 39, n.2, p.285-292. 1973.

Shannon, M. C. Adaptation of plants of salinity. Advances in Agonomy, San Diego, v.60, n.1, p.75-120, 1997.

Travis, I. Gene makes tomato tolerate salts, Science News, Washington, v.160, n.5, p.68. 2001.

World Bank//UNDP. Irrigation and drainage research. Washington, DC: World Bank/UNDP. 1990, 19p.

Yeo, A. Predicting the interaction between the effects of salinity and climate change on crop plants. Scientia Horticulturae, Amsterdam, v.78, n.1, p.159-174, 1999. 